\title{
EARTHQUAKE RISK MITIGATION: THE IMPACT OF SEISMIC RETROFITTING STRATEGIES ON URBAN RESILIENCE
}

\author{
Tiago Miguel FERREIRA a,*, Rui MAIO a, Romeu VICENTE a, Aníbal COSTA a \\ a RISCO, Department of Civil Engineering, University of Aveiro, Campus Universitário de Santiago, \\ 3810-193, Aveiro, Portugal
}

Received 27 March 2015; accepted 29 September 2015

\begin{abstract}
It is recognized that both community and urban resilience depends on the capacity of built environment to maintain acceptable structural safety levels during and after unforeseeable events, such as earthquakes, as well as to recover their original functionality. Investing in disaster risk mitigation policies is a great step towards promoting urban resilience and community preparedness, implicitly limiting damage to the built environment and subsequently reducing human, economic and environmental losses. Portugal is a moderate to high seismic prone area as the latest estimates indicate that within the next 50 years the country could be severely hit by a strong quake similar to the historical 1755 event, which left a trail of destruction and death, mainly in densely populated areas, such as Lisbon. This manuscript aims to mitigate the impact of earthquake damage scenarios on social and economical terms, as well as evaluating the outcome of implementing traditional retrofitting strategies to existing masonry building stock located in urban areas of high seismic risk, using the old city centre of Horta, Faial Island (Azores, Portugal), as a case study.
\end{abstract}

KEYWORDS: Built environment; Resilience; Risk mitigation; Seismic vulnerability; Retrofitting solutions; Loss estimation

\section{INTRODUCTION: URBAN RESILIENCE AND EARTHQUAKE RISK MITIGATION}

The concept of urban resilience is often defined as the ability of exposed communities to sustainably resist, support and recover from the effects of hazards and is directly connected to mitigation, preparedness, disaster, response, recovery and reconstruction disaster risk management phases (Coaffee 2008). With this work, the authors aim at contributing for infrastructural resilience and seismic risk mitigation of historical city centres' built environment, since they are frequently vulnerable areas, with safeguarding importance. Before embracing our particular focus, one should acknowledge the consequences and impact of natural disasters at a global scale from previous learning experiences, as well as be aware of successful strategies and practices carried out recently all over the world and at a large assessment scale, in terms of communities' resilience. In this sense, risk identification from natural hazards is considered the first step towards reducing their adverse

\footnotetext{
* Corresponding author. E-mail: tmferreira@ua.pt
}

effects. Several organisations such as GFDRR (Global Facility for Disaster Reduction and Recovery) are committed on helping governments and communities in vulnerable disaster-prone areas by increasing the perception, awareness and access to comprehensive information about physical and societal exposure to disaster risk (Arshad, Athar 2013). This way, governments, communities, and private stakeholders are able to better quantify and predict potential impacts of natural hazards on both society and economy, and also to carry out risk-sensitive decision-making. Moreover, these global knowledge-sharing partnerships usually work together along with governments, civil society and the private sector to create and improve the policies and legislation needed for better land use planning, to drive investment aimed at risk mitigation and acting as a moderator over the often-difficult dialogue between stakeholders (Arshad, Athar 2013).

As seismic hazard is still ruled by its unpredictability and insusceptibility to be completely eliminated, preparedness and awareness by means of 
developing and optimising contingency and emergency response plans, are therefore mandatory strategies to save lives and protect communities. Even so, as communities can still be highly exposed to financial shocks, it is necessary the development and implementation of adequate disaster risk financial protection strategies, allowing a quicker and balanced response, improving the resilience of all stakeholders. Education plays a crucial role on this process, as several educational programs have been conducted to promote cooperation and innovation among Higher Education Institutions to increase society's resilience to disaster of both human and natural origin, as the case of the ANDROID academic network. Created in the framework of the ANDROID Working Package 7, this working group has focused their research on the vulnerability and resilience in multi-hazard scenarios for the Venice lagoon case study (Kaluarachchi et al. 2014; Indirli et al. 2014; Knezic et al. 2014; Borg et al. 2014). The complexity of this case study concerns the probability of occurrence of cross-border multi-hazard disastrous events that possibility may involve other surrounding countries such as Slovenia and Croatia. Moreover, there are multiple variables involved: population; heritage; environment; Industrial facilities; tourism; the lagoon itself, the surrounding islands and the mainland territory.

There are several successful examples of the positive influence of disaster risk management and planning on communities' resilient capacity, as the case of the RHRP (Rural Housing Reconstruction Program) in the aftermath of the October 2005 earthquake in northern Pakistan, which roughly caused 73,000 deaths and more than 2.8 million homeless people (Arshad, Athar 2013), the February 2010 Chile (Astroza et al. 2012) or the February 2011 Christchurch earthquakes (Mitchelson 2011). Moreover, the March 2011 GEJE (Great East Japan Earthquake), the first ever recorded mega-disaster comprehending earthquake, tsunami, nuclear power plant accident, power supply failure and large-scale disruption of supply chains, caused 20,000 casualties, over than 130,000 collapsed buildings and 270,000 severely damaged, with a direct economic cost estimated in $\$ 210$ billion (Ranghieri, Ishiwatari 2014). Although Japan's community preparedness is internationally acclaimed and disaster risk management strategies had been developed and implemented for decades, no one could ever have foreseen this complexity derived from the 9.0 magnitude earthquake cascading effects.
In many countries, including Portugal, civil protection bodies are the agencies responsible for the general emergency response plan, which covers all types of hazards (natural and man-made), both before and after an event. So that they can fulfil this task, the agents involved in planning earthquake risk mitigation strategies should be able to define which zones are physically more vulnerable and to prepare logistic and field exercises to simulate situations that may arise in a real earthquake situation (Goula et al. 2006). However, as discussed by Ferreira et al. (2013), risk management of urban areas is frequently undertaken without the use of a general planning tool. A primary consequence of this situation is that technicians and decision makers (city councils or regional authorities) do not have a global view of the area under analysis, which can seriously commit the effectiveness of future rehabilitation strategies and risk mitigation measures. Several authors have been taking the advantage of these multi-purpose tools on hazard and vulnerability related projects, as those carried out by Indirli (2009) for the historical centre of San Giuliano di Puglia (in Italy) and the city of Valparaiso (in Chile), or for the Vesuvian region in Italy (Mazzolani et al. 2009). Hence, with this paper, the authors intend to bring attention to this matter, through better understanding the cost-to-benefit balance of seismic retrofitting of old masonry buildings located in historical centres. Furthermore, it is expected that the outputs resulting from this work can contribute to clarify the common ideas that there is no need for seismic retrofitting in Portugal and that these interventions are too expensive

\section{SEISMIC VULNERABILITY ASSESSMENT AND RETROFITTING SOLUTIONS}

\subsection{The case study of the old city centre of Horta, Portugal}

The present case study concerns the seismic vulnerability assessment of the city centre of Horta, in Faial Island, Azores. This island was severely hit by the July 9, 1998 Azores earthquake, leaving a trail of destruction (roughly $70 \%$ of the built environment), affecting directly more than 5000 people and causing 8 deaths, 150 injured and 1500 homeless. All data and information collected during the 10-year reconstruction process of Faial Island (hereinafter designated by Faial database), conducted by the Society of Promotion for Housing and Infrastructures Rehabilitation (SPRHI), was 
gathered over an 8-month-length period in 2007 by the Regional Secretariat for Housing and Equipment (SRHE) of the Faial Island, which funded this initiative (Neves et al. 2012a). The quality and uniqueness of this database in both national and international context have encouraged the development of several advanced studies throughout the years. Even though the fully open access provided to the mentioned database collected in the aftermath of the 1998 earthquake, the authors carried out in field surveying work, prospected in the scope of the FCT URBSIS project (Assessing Vulnerability and Managing Earthquake Risk at the Urban Scale), collecting appraisal data in order to understand the evolution and diachronic process resulting from rehabilitation interventions implemented since 1998. Although the damage levels observed in the built environment of Horta were not as severe as in the remaining parishes of the Faial Island, classified with a macroseismic intensity $I_{\text {EMS-98 }}=$ V/VI (Zonno et al. 2010), this urban area was still selected as case study due to its importance in both cultural and architectural heritage context. Moreover, taking into consideration the goal of the present work, the authors based their assessment on the existing building condition at the time of the earthquake that hit Faial Island in 1998, before likely late comprehensive retrofitting actions ever occurred, hereinafter designated as BR (before retrofitting).

When performing vulnerability assessment of a large number of buildings and over an urban centre or region, the resources and quantity of information to collect and deal with can be enormous and thus the use of more expedite approaches results more adequate and reasonable. Methodologies for vulnerability assessment either at the national and urban scale should be based on few parameters, defined through the knowledge of the effects of past earthquakes, which can then be treated statistically (Neves et al. 2012b). The definition and nature of such approach (qualitative and quantitative) naturally limits the formulation of the methodologies and the level at which the evaluation is conducted, from the expedite evaluation of buildings based on visual observation to the most complex numerical modeling of single structures.

Despite several different methodologies have been developed and validated during the last decades, such as the FAMIVE method (D'Ayala, Speranza 2002) or the MEDEA procedure (MEDEA 2013) - which the results were compared by Indirli et al. (2013) - the seismic vulnerability of the old city centre of Horta was evaluated in this work using the vulnerability index methodology developed by Vicente (2008) on the basis of the Italian GNDT II level approach (GNDT 1994). It is worth noting that this methodology has been used in recent years for the seismic vulnerability assessment of several historical urban centres in Portugal (see Vicente et al. 2011; Ferreira et al. 2013; Maio et al. 2015).

Similarly to above mentioned past surveying and assessment case studies, the difficulties encountered in accessing the interior of all the buildings and time constraint related issues, led the authors to distinguishing two different assessment levels. Thus, a total of 313 buildings were divided into four different groups based on the detail level of the available information. The first group (Detailed assessment), composed of the 50 buildings for which a detailed inspection was undertaken, was evaluated resorting to detailed specific information such as architectural and structural plans, photographic and post-earthquake damage reports, gathered in the Faial database, allowing for the full evaluation of the required input parameters of the vulnerability index methodology used. The second group was composed of 142 buildings for which only a non-detailed exterior inspection was available (Non-detailed assessment). A third group composed of 93 reinforced concrete buildings was not included in this study as the used vulnerability index methodology is only suitable for masonry building typologies. Finally, a fourth group was created to include other 28 non-assessable buildings related to religious or governmental use, and also buildings in pre-ruin or buildings undergoing a retrofitting process. Thus, the outputs of mean vulnerability index values presented further on, were obtained through assembling both detailed and non-detailed assessment groups, hereinafter designated as overall assessment.

The seismic vulnerability index methodology herein applied, classified by Calvi et al. (2006) as an hybrid technique suitable for large-scale assessment of masonry buildings, comprehends the calculation of a vulnerability index score, $I_{v}^{*}$, for each building as the weighted sum of 14 parameters (in Eq. 1), each one of them evaluating one aspect related to the building's seismic response, distributed into four vulnerability classes $\left(C_{v i}\right)$ of growing vulnerability, from $\mathrm{A}$ to $\mathrm{D}$ (Vicente et al. 2011).

$$
I_{v}^{*}=\sum_{i=1}^{14} C_{v i} \times p_{i} .
$$


Table 1. Vulnerability index methodology (Vicente 2008)

\begin{tabular}{|c|c|c|c|c|c|c|}
\hline \multirow[t]{2}{*}{ Parameters by group } & \multicolumn{4}{|c|}{ Class $C_{v i}$} & \multirow{2}{*}{$\begin{array}{l}\text { Weight } \\
p_{i}\end{array}$} & \multirow{2}{*}{$\begin{array}{l}\text { Relative weight } \\
\text { over } I_{v}^{*}\end{array}$} \\
\hline & $\mathrm{A}$ & $\mathrm{B}$ & $\mathrm{C}$ & $\mathrm{D}$ & & \\
\hline \multicolumn{7}{|l|}{ 1. Structural building system } \\
\hline P1 Type of resisting system & 0 & 5 & 20 & 50 & 0.75 & $46 / 100$ \\
\hline P2 Quality of resisting system & 0 & 5 & 20 & 50 & 1.00 & \\
\hline P3 Conventional strength & 0 & 5 & 20 & 50 & 1.50 & \\
\hline P4 Maximum distance between walls & 0 & 5 & 20 & 50 & 0.50 & \\
\hline P5 Number of floors & 0 & 5 & 20 & 50 & 1.50 & \\
\hline P6 Location and soil conditions & 0 & 5 & 20 & 50 & 0.75 & \\
\hline \multicolumn{7}{|l|}{ 2. Irregularities and interactions } \\
\hline P7 Aggregate position and interaction & 0 & 5 & 20 & 50 & 1.50 & $27 / 100$ \\
\hline P8 Plan configuration & 0 & 5 & 20 & 50 & 0.75 & \\
\hline P9 Height regularity & 0 & 5 & 20 & 50 & 0.75 & \\
\hline \multicolumn{7}{|l|}{ 3. Floor slabs and roofs } \\
\hline P10 Wall façade openings and alignments & 0 & 5 & 20 & 50 & 0.50 & $15 / 100$ \\
\hline P11 Horizontal diaphragms & 0 & 5 & 20 & 50 & 1.00 & \\
\hline P12 Roofing system & 0 & 5 & 20 & 50 & 1.00 & \\
\hline \multicolumn{7}{|l|}{ 4. Conservation status and other elements } \\
\hline P13 Fragilities and conservation status & 0 & 5 & 20 & 50 & 1.00 & $12 / 100$ \\
\hline P14 Non-structural elements & 0 & 5 & 20 & 50 & 0.50 & \\
\hline
\end{tabular}

Subsequently, a weight $p_{i}$, is assigned to each parameter, ranging from 0.50 for the less important parameters (in terms of structural vulnerability) up to 1.50 for the most important ones. The initial value of $I_{v}^{*}$, ranging in between 0 and 650 , is then normalised to vary in between 0 and 100, designated as $I_{v}$ to further ease of use, namely when estimating the building's damage condition based on different macroseismic intensities (Grünthal 1998) and also in both human and economic loss estimation. According to the Table 1, these 14 parameters are arranged into four groups to emphasize their differences and relative importance on the global seismic response of the building.

According to the previous definition of the Detailed assessment group (first inspection phase), the evaluation of the vulnerability index was made for those buildings to which detailed information was available (50 buildings out of 313). Accordingly, a more expeditious approach for the Nondetailed assessment group of the remaining 142 buildings was conducted (second inspection phase), using the mean values obtained from the Detailed analysis of the first group of buildings, assuming the masonry building characteristics homogeneous in this area. Starting from this principle, the mean vulnerability index value obtained in the first $D e$ tailed evaluation was used as a typological vulnerability index (mean value) that could be affected by modifiers of the mean vulnerability index for each building (Ferreira et al. 2013). The classification of these modifiers influenced the final vulnerability index as a sum of the scores for all modifiers. Thus, the vulnerability index of each Non-detailed building, $\overline{\bar{I}}_{v}$, is defined in the following Eq. 2:

$$
\overline{\bar{I}}_{v}=\overline{I_{v}}+\sum \Delta I_{v}
$$

where: $\overline{I_{v}}$ is the mean vulnerability index resulting from the Detailed assessment, and $\sum \Delta I_{v}$ is the sum of the modifier scores for the attributed class. It is important to note that this strategy is valid only if a reliable Detailed assessment of a large number of buildings in the study area is initially obtained and the strategy is applied to a single building typology (Santos et al. 2013).

The following Eq. (3) shows how the scores of each modifier parameter class was estimated:

$$
\frac{p_{i}}{\sum_{i=1}^{6} p_{i}} \times\left(C_{v i}-\overline{C_{v i}}\right),
$$

where: $p_{i}$ is the weight assigned to parameter $i$; $\sum_{i=1}^{6} p_{i}$ is the sum of parameter's weights; $C_{v i}$ is the modifier factor for a determined vulnerability class and $\overline{C_{v i}}$ is the mean vulnerability class of parameter $i$, defined by the Detailed assessment.

From the application of the vulnerability index methodology described above to the 50 buildings assessed in a Detailed manner, corresponding to the first inspection phase, a mean value of the seismic vulnerability index, $\overline{I_{v}}$, of 26.32 was obtained, to which was associated a standard deviation 
value, $\sigma_{\overline{I_{v}}}$ of 9.73 . Assembling the complementary approach, used in the Non-detailed assessment of the remaining 142 buildings to which the available information was somehow incomplete (second phase of assessment), an overall assessment seismic vulnerability index mean value, $\bar{I}_{v O A}$, of 26.55 with a corresponding standard deviation value, $\sigma_{\overline{I_{v O A}}}$, of 5.45 , was estimated. The maximum and minimum $I_{v}$ index values obtained from the detailed assessment were evaluated in 55.00 and 10.96, respectively. It is important to note that the results obtained for the BR building condition are well adjusted to the building characteristics and fragilities the assessed buildings, an evidence of the method's robust nature.

\subsection{Application of traditional retrofitting solutions}

The protection of the lives of building occupants in the event of an earthquake is the main goal of the retrofit, referred as "life safety" performance in building codes. In many cases the life safety level prescribed by building codes cannot be achieved without major structural intervention and investment. Thus, retrofitting is considered to be unfeasible when the required capital investment exceeds the initial building cost, or when a building is in an advanced degradation state or in pre-ruin. Costs associated with demolition, debris disposal and reconstruction determine the feasibility of each retrofit project. Moreover, legal issues arise when the safety of a building is dependent on adjacent housing units, like in the case of row buildings where several owners share a building, and housing units with different owners have a common wall. Retrofitting a single house in row housing has low benefit when adjacent units are seismically deficient (Bothara, Brzev 2011).

Although the establishment of retrofit strategies for a specific building depends on socio-economic constraints, a number of technical issues arise, such as: structural system; building ma- terials; quality of construction; building and site conditions; intensity of damage sustained by the building in past earthquakes; and the expected ground shaking in the area. The following strategies have been point out by Bothara and Brzev (2011) as presenting the highest cost-to-benefit ratio in terms of improving the seismic safety of stone masonry buildings: i) enhancing integrity of the entire building by ensuring the box-like seismic behaviour; ii) enhancing the wall strength for in-plane and out-of-plane effects of seismic loads; improving floor and roof diaphragm action; and finally, iii) the strengthening of the existing foundation, which strategy is not considered practical and economically feasible in most cases.

As massive demolition and replacement of this vulnerable building typology seems neither affordable nor feasible due to historical, cultural, social and economic constraints, this section presents the retrofitting strategies adopted in this study, which are based on the reconstruction methodology defined shortly after the 1998 earthquake by the Regional government of Azores, aiming to enhance the seismic performance, and thus the vulnerability of existing stone masonry buildings, through retrofitting solutions that comply with the mentioned constraints. Bearing in mind the exposed, six retrofitting solutions of increasing intrusiveness and cost (from S1 to S6), grouped into three cumulative retrofitting packages (from RP1 to RP3), were herein addressed (see Table 2).

These solutions were adopted in the aftermath of the 1980 and 1998 Azores earthquakes by different design offices based on the design recommendations specially prepared for the Faial rehabilitation process (Cansado et al. 1998), developed by the Civil Engineering Regional Laboratory of Azores (LREC) in partnership with several experienced technicians in this field (Oliveira et al. 1990; Costa et al. 2008). The costs associated to each package (presented in Table 2) were defined by Costa et al. (2008) from a sample of 40 structural design projects that undergone a thorough

Table 2. Seismic retrofitting solutions adopted

\begin{tabular}{llll}
\hline $\begin{array}{l}\text { Retrofitting } \\
\text { packages }\end{array}$ & $\begin{array}{l}\text { Retrofitting } \\
\text { solution }\end{array}$ & Description & $\begin{array}{l}\text { Estimated cost } \\
\text { in } € / \mathrm{m}^{2}\end{array}$ \\
\hline RP1 = S1 + S2 + & S1 & Wall-to-wall connection improvement through tie-rods & 35 \\
S3 + S4 & S2 & Floors stiffening with diagonal bracing and new timber planks & \\
& S3 & Wall-to-floor connection improvement & \\
& S4 & Wall-to-roof connection improvement through tie-rods & \\
RP2 = RP1 + S5 & S5 & Wall-to-roof connection improvement through concrete strapping & 100 \\
& & beam & 230 \\
RP3 = RP2 + S6 & S6 & Stone masonry consolidation through reinforced plasters & 230 \\
\hline
\end{tabular}


analysis process. As the adopted strategy pursues the cumulative implementation of retrofitting solutions and the authors have considered this set of retrofitting solutions effective on enhancing the box-like behaviour of stone masonry buildings, resorting to low-to-moderate intrusiveness and estimated costs, the following solutions $\mathrm{S} 1$ to $\mathrm{S} 4$ were grouped in RP1 package (shown in Figs 1 and 2).

The retrofitting of wall-to-wall connections by means of effectively tying walls together with steel tie-rods, addressed in the retrofitting solution $\mathrm{S} 1$, is an ancient provision to enhance the building integrity, seen as a crucial requirement for survival during an earthquake, which has been used for many centuries in Mediterranean European countries, such as Italy. With diameters ranging normally from 16 to $20 \mathrm{~mm}$ (Bothara, Brzev 2011), these threaded steel tie-rods are installed horizontally beneath floors (S1) or roofs (S4) on both sides of the wall, and are restrained at the ends by steel anchor plates, as depicted in Figure 1 (a), adapted from Cansado et al. (1998), D'Ayala and Speranza (2002). This solution is not only effective in increasing the stiffness of flexible floor diaphragms but also in enhancing the connections with exterior load-bearing walls and frontal walls.

Moreover, through the assessment of the stone masonry building stock under study, the authors have confirmed the predominance of flexible timber floors, many of which besides aging have been deteriorated over time. Furthermore replacing all deteriorated structural timber elements of floors diaphragms by new parts adequately connected, restoring their original resistant capacity, the solution adopted in this study for retrofitting of floor connections (S2), joins two different stiffening pro- visions: the installation of $75 \mathrm{~mm}$ thick diagonal wood braces at the floor level between principal timber beams, anchored with $\phi 10$ galvanized steel threaded rods of and $3 \mathrm{~mm}$ thick galvanized steel angle brackets, and a new layer of timber planks, laid perpendicular to the existing planks and adequately nailed to the floor as shown in Figure 1 (b).

The retrofitting of wall-to-floor connections solution (S3) was enhanced by introducing $3 \mathrm{~mm}$ thick full-length steel angle brackets adequately anchored to walls through steel connectors and anchor plates, as depicted in Figure 2 (a), complementing the previous solution S2. Finally, Figure 2 (b) illustrates the retrofitting of wall-to-roof connections solution (S4), ensured by applying the same technique as in solution S1 but at the roof level, by introducing steel tie-rods underneath the ceiling joists, to sustain horizontal thrusts in the event of an earthquake.

The retrofitting package RP2 adds the retrofitting solution S5 to the previous package RP1, comprehending the introduction of a reinforced concrete strapping beam (with $4 \phi 10$ longitudinal steel bars and $\phi 6 / / .20$ stirrups) at the top of stone masonry walls, executed along the whole perimeter of the building, enhancing the connection between roof and load-bearing stone masonry, see Figure 3 (a). In the same figure it is also illustrated a strengthening detail of the connection between the roof and gable masonry walls.

Retrofitting package RP3 comprises retrofitting solution S6, presented in Figure 3 (b), which involves the shear strengthening and confinement of masonry structural walls by the implementation of reinforced render, as specified in Costa (2002). Thus, after application of a first layer of

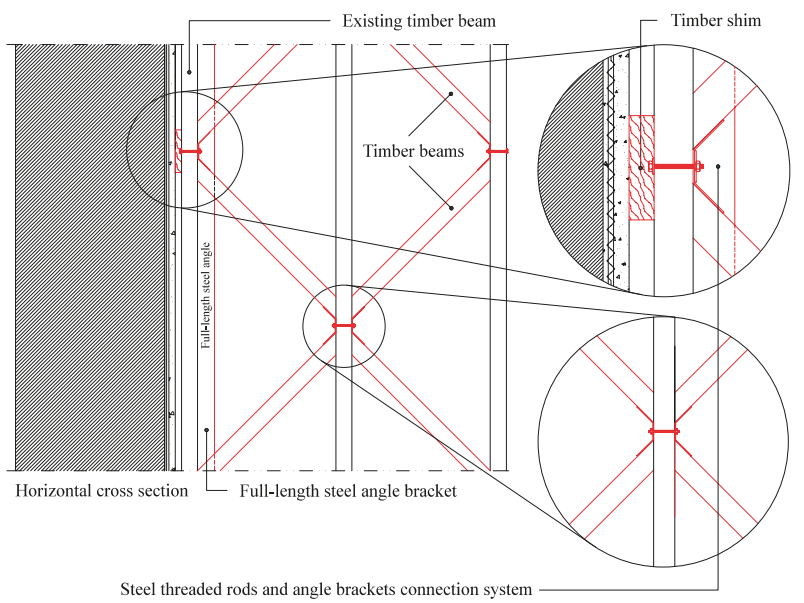

(b) Retrofitting solution S2 (a) Retrofitting solution S1

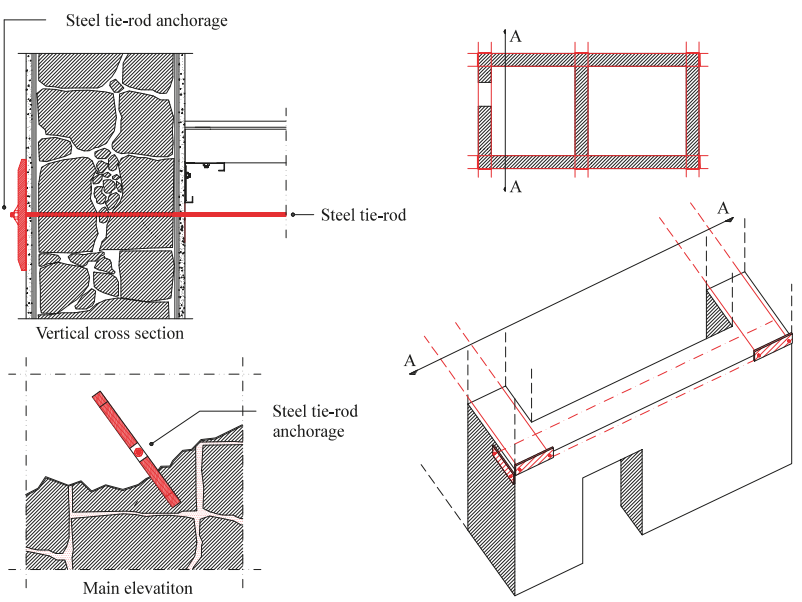

Fig. 1. Details of retrofitting solutions S1 (a) and S2 (b) of package RP1, adapted from Costa (2006) 




(a) Retrofitting solution S3



(b) Retrofitting solution S4

Fig. 2. Details of retrofitting solutions S3 (a) and S4 (b) of package RP1, adapted from Costa (2006)

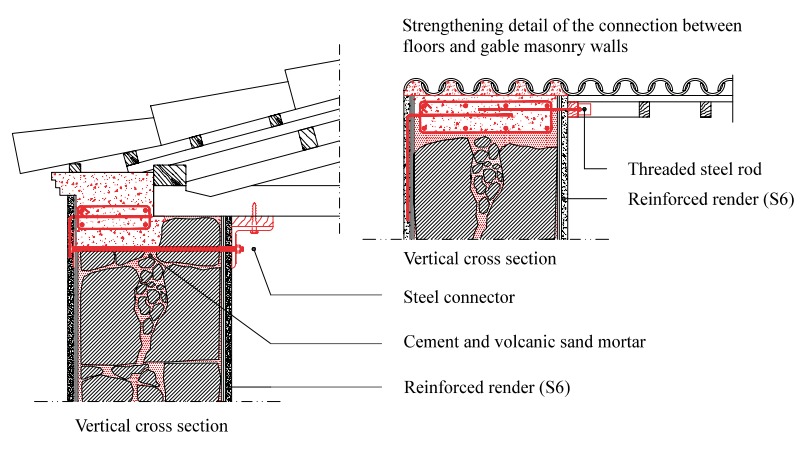

(a) Retrofitting solution S5

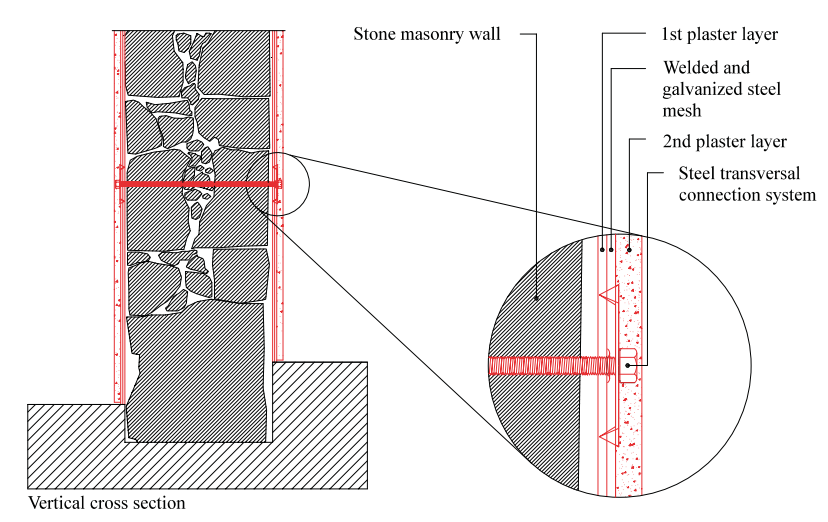

(b) Retrofitting solution S6

Fig. 3. Details of retrofitting solutions S5 of package RP2 (a) and S6 of RP3 (b), adapted from Costa (2006)

filling mortar in the proportion of 1:3 (local sand extracted from Fajã Beach: Portland cement: water) for voids and surface regularisation, a $0.5 \mathrm{~mm}$ thick welded steel mesh made of Fe430 steel and $10 \mathrm{~cm}$ spaced ribs, is then fixed on both sides of the masonry wall through a system composed of M20 galvanized screws, $\phi 20$ galvanized steel threaded rods and $4 \mathrm{~mm}$ thick anchor plates $(20 \times 20 \mathrm{~mm})$, spaced of $150 \mathrm{~cm}$. Finally, a $3 \mathrm{~cm}$ thick second layer of fine sand-blasted finishing mortar is applied for finishing (Costa 2002).

\section{COMPARATIVE ANALYSIS}

\subsection{Seismic vulnerability assessment}

Following the previous section wherein the retrofitting solutions and packages were presented, the current section begins by explaining how exactly these retrofitting solutions were accounted on the seismic vulnerability index methodology herein used. According to the following Table 3, each retrofitting solution has directly contributed to the gradual enhancement of the vulnerability index value $I_{v}$, by upgrading the vulnerability classes $C_{v i}$, of parameters $\mathrm{P} 1, \mathrm{P} 2, \mathrm{P} 3, \mathrm{P} 11, \mathrm{P} 12$ and $\mathrm{P} 13$. It is important to refer that these solutions were cumulatively implemented, from S1 to S6. With the exception of retrofitting solutions S4 and S6 that do not define directly the vulnerability class upgrade, the remaining vulnerability classes presented in Table 3 were directly attributed to all the evaluated buildings.

While retrofitting solution S4 the enhancement was simply guaranteed by improving in one class the original vulnerability class $C_{v i}$ of parameter $\mathrm{P} 12$, the explanation concerning retrofitting solution S6, influencing over parameter P3, requires deeper attention. Acknowledging the fact that in an urban context, as in the present case study, the observed masonry typology and fabric is quite 
Table 3. Influence of each retrofitting solution over the vulnerability index value, $I_{v}$

\begin{tabular}{|c|c|c|c|c|}
\hline $\begin{array}{l}\text { Retrofitting } \\
\text { packages }\end{array}$ & $\begin{array}{l}\text { Retrofitting } \\
\text { solution }\end{array}$ & Description & Parameter & $\begin{array}{l}\text { Vulnerability } \\
\text { class, } C_{v i}\end{array}$ \\
\hline \multirow[t]{4}{*}{$\begin{array}{l}\mathrm{RP} 1= \\
\mathrm{S} 1+\mathrm{S} 2+\mathrm{S} 3+\mathrm{S} 4\end{array}$} & S1 & $\begin{array}{l}\text { Wall-to-wall connection improvement through } \\
\text { tie-rods }\end{array}$ & $\mathrm{P} 1$ & $\mathrm{~B}$ \\
\hline & S2 & $\begin{array}{l}\text { Floors stiffening with diagonal bracing and new } \\
\text { timber planks }\end{array}$ & P11 & $\mathrm{A}$ \\
\hline & S3 & Wall-to-floor connection improvement & P1 & $\mathrm{A}$ \\
\hline & $\mathrm{S} 4$ & $\begin{array}{l}\text { Wall-to-roof connection improvement through } \\
\text { tie-rods }\end{array}$ & $\mathrm{P} 12$ & +1 \\
\hline $\mathrm{RP} 2=\mathrm{P} 1+\mathrm{S} 5$ & S5 & $\begin{array}{l}\text { Wall-to-roof connection improvement through } \\
\text { concrete strapping beam }\end{array}$ & $\mathrm{P} 12$ & $\mathrm{~A}$ \\
\hline $\mathrm{RP} 3=\mathrm{P} 2+\mathrm{S} 6$ & $\mathrm{~S} 6$ & $\begin{array}{l}\text { Stone masonry consolidation through reinforced } \\
\text { plasters }\end{array}$ & $\begin{array}{l}\text { P2 } \\
\text { P3 } \\
\text { P13 }\end{array}$ & $\begin{array}{l}\mathrm{A} \\
\tau_{0} \\
\mathrm{~A}\end{array}$ \\
\hline
\end{tabular}

distinct than in rural areas and in order to estimate reliable values for the stone masonry buildings within the city centre of Horta, the authors have matched the masonry typological classification argued by Costa (2002) with the Italian Seismic Code (DM 2008) classification and corresponding mechanical properties of those masonry typologies. Through observing the available information collected in the aftermath of the 1998 earthquake, it was possible to clearly differentiate two masonry typologies: i) Type M1, masonry walls of good quality, built with regular size stones, which is described in NTC 2008 (DM 2008) as "Masonry in squared stony blocks" and is commonly observed in the noblest and most magnificent Azorean buildings; and ii) Type M3, masonry walls of irregular stones interconnected using smaller fragments of stone or clay to fill in the small voids and to ensure adequate strength, described in NTC 2008 (DM 2008) as "Masonry in disorganized (irregular) stones typology".

Accordingly, for masonry Type M1, the values adopted for the mechanical properties of the material are based on the corresponding lower limit of NTC 2008 guidelines (DM 2008), which are in line with those adopted in past research works carried out within the same urban area of the city of Horta (Neves et al. 2012b; Cunha 2013). For masonry Type M3, the value considered was obtained from the experimental work developed by Costa et al. (2012). Thus, by introducing retrofitting solution S6 (of RP3), ultimate shear strength value $\tau_{0}$ , required to estimate the conventional strength in parameter P3, were enhanced in about $60 \%$ and $110 \%$ for the masonry typology M1 and M3, respectively. As mentioned in Section 2.1, the seismic vulnerability index mean value, $\bar{I}_{v O A}$, of 26.55 was obtained for the BR building stock condition, reflecting the good general quality of these buildings within the current urban environment, namely features regarding building's geometry and global alignments, as in P4, P5, P7, P8, P9 and P10.

The application of the same vulnerability index methodology considering the retrofitting package $\mathrm{RP} 1$, led to a reduction of the seismic vulnerability index mean value, $\bar{I}_{v O A}$, of roughly $18.9 \%$. Moreover, introducing the retrofitting package RP2, this reduction slightly increased to $23.1 \%$, again when compared to the BR vulnerability index mean value. Finally, by considering the retrofitting package RP3 (which includes the previous packages RP1 and RP2), the seismic vulnerability index mean value was reduced in $51.7 \%$. The results in terms of seismic vulnerability index values are summarised in the following Table 4, as well as the attained reduction of $\bar{I}_{v O A}$ for each retrofitting package $\left(\mathrm{RP}_{\mathrm{i}}\right)$ with respect to the original building condition (BR).

Table 4. Vulnerability index values and reduction values

\begin{tabular}{|c|c|c|c|c|c|}
\hline \multirow{2}{*}{$\begin{array}{l}\text { Build- } \\
\text { ing con- } \\
\text { dition }\end{array}$} & \multicolumn{2}{|c|}{$\begin{array}{l}\text { Detailed assess- } \\
\text { ment }\end{array}$} & \multicolumn{2}{|c|}{$\begin{array}{l}\text { Overall assess- } \\
\text { ment }\end{array}$} & \multirow{2}{*}{$\begin{array}{l}\text { Reduc- } \\
\text { tion } \\
-(\%)\end{array}$} \\
\hline & $\overline{I_{v}}$ & $\sigma_{\overline{I_{v}}}$ & ${\overline{I_{v}}}_{O A}$ & $\sigma_{\overline{I_{v}}}$ & \\
\hline BR & 26.32 & 9.73 & 26.55 & 5.45 & - \\
\hline $\mathrm{RP} 1$ & 21.30 & 7.64 & 21.52 & 4.52 & 18.9 \\
\hline RP2 & 20.19 & 7.18 & 20.41 & 4.32 & 23.1 \\
\hline RP3 & 12.61 & 4.72 & 12.84 & 3.34 & 51.7 \\
\hline
\end{tabular}

\subsection{Damage scenarios and loss estimation}

This section presents loss estimation obtained for different damage scenarios computed for several macroseismic intensities, $I_{\text {EMS-98. According to }}$ Nunes (2008), ever since the second half of the $20^{\text {th }}$ century, maximum intensities of $I_{\text {EMS-98 }}=$ VII and VIII were observed in the Azorean archipelago, during the earthquakes of 1952 (São Miguel), 1964 
(São Jorge), 1973 (Pico) and 1988 (São Miguel). Moreover, maximum intensities of $I_{\mathrm{EMS}-98}=\mathrm{IX}$ were recorded in 1958, 1980 and 1998.

Among the several methods described in the literature for estimating losses in function of the probability of occurrence of a certain damage grade, this task was herein carried out through the construction of damage scenarios based on global probabilistic distributions, using the seismic vulnerability index values, $I_{v}$, obtained to the different above-mentioned building conditions (BR, RP1, RP2 and RP3). The damage estimation models are inevitably dependent on the physical damage grades, including the definition of correlations between the probability of exceeding a certain level of damage and the probability of different loss phenomena (such as the probability of collapsing or becoming unusable due to the lack of structural safety conditions, the probability of death and severely injured, etc.). Thus, and based on the previously discussed seismic vulnerability assessment outputs, mean damage grades, $\mu_{D}$, were estimated and discussed next for different macroseismic intensities, based on each building vulnerability index, $I_{v}$. To this end, Bernardini et al. (2007) proposed an analytical expression that correlates hazard with the mean damage grade ( $\left.0 \leq \mu_{D} \leq 5\right)$ of the damage distribution in terms of vulnerability value, Eq. (4):

$$
\begin{aligned}
& \mu_{D}=2.5 \times\left[1+\tanh \left(\frac{I+6.25 \times V-13.1}{Q}\right)\right] ; \\
& 0 \leq \mu_{D} \leq 5,
\end{aligned}
$$

where: $I$ is the macroseismic intensity in accordance to the European Macroseismic Scale (EMS98); $V$ is the vulnerability index used in the macroseismic methodology, which can be related to the vulnerability index value $I_{v}$, through Eq. (5); and $Q$, which is a ductility factor that describes the ductility of the constructive typology under study (ranging from 1 to 4). In order to provide the best fit between the GNDT curves and the EMS-98 functions, a ductility factor, $Q$, of 3.0 was adopted in this work (see Vicente et al. 2011; Ferreira et al. 2013).

$$
V=0.592+0.0057 \times I_{v}
$$

Globally, the estimated damage for the original building condition (BR) ranged from 2.49 to 3.69 and 3.30 to 4.23 for earthquake scenarios corresponding to $I_{\mathrm{EMS}-98}=\mathrm{IX}$ and $I_{\mathrm{EMS}-98}=\mathrm{X}$, respectively. When the Retrofitting Package RP3 is applied to the building stock of Horta, the values obtained for the mean damage grade decrease substantially, ranging between 2.30 and 2.88 and from 3.12 to 3.63 (minimum and maximum) for macroseismic intensities of $I_{\text {EMS-98 }}=$ IX and $I_{\text {EMS. }}$ ${ }_{98}=\mathrm{X}$, respectively. In this sense it is pertinent to note that according to some authors (Pagnini et al. 2011; Vicente et al. 2011; Ferreira et al. 2013), buildings with a vulnerability index higher than 45 , i.e. building for which severe damages $\left(3 \leq \mu_{D} \leq 4\right)$ and potential local collapse $\left(\mu_{D}>4\right)$ are expected, should be subjected to a further assessment resorting to a more detailed approach.

The loss estimation model adopted in this research is based on damage grades that relate the probability of exceeding a certain damage level with the probability of collapse and functional loss. Supported on observed damage data, the approach herein applied has been proposed by Servizio Sísmico Nazionale (SSN) based on the work of Bramerini et al. (1995). This approach involves the analysis of data associated with the probability of buildings to be deemed unusable after minor and moderate seismic action. As referred in Maio et al. (2015), although such events produce lower levels of structural and non-structural damage, higher mean damage grade values are associated with a higher probability of building collapse. The probabilities of exceeding a certain damage grade are used in the loss estimation and are affected by multiplier factors, which range from 0 to 1 according to different proposals. In Italy, data processing undertaken by Bramerini et al. (1995) has enabled the establishment of these weighted factors and respective expressions for their use in the estimation of building losses.

The following Eq. (6) and (7) were used for the determination of collapsed and unusable buildings:

$$
\begin{aligned}
& P_{\text {collapse }}=P\left(D_{5}\right), \\
& P_{\text {unusable buildings }}=P\left(D_{3}\right) \times W_{e i, 3}+P\left(D_{4}\right) \times W_{e i, 4},
\end{aligned}
$$

where: $P\left(D_{i}\right)$ is the probability of the occurrence of a certain damage grade (from $D_{1}$ to $D_{5}$ ) and $W_{e i, j}$ are multiplier factors that indicate the percentage of buildings associated with the damage grades; $D_{i}$, that suffer collapse or are considered unusable. Following the work of Maio et al. (2015), these multiplier factors are assumed here as $W_{e i, 3}=0.4$ and $W_{e i, 4}=0.6$. Figure 4 presents the probability of building collapse and unusable buildings for the four building conditions studied in this work (BR, RP1, RP2 and RP3).

Moreover, Table 5 summarizes the overall results in terms of collapsed and unusable buildings, obtained for those building conditions by 


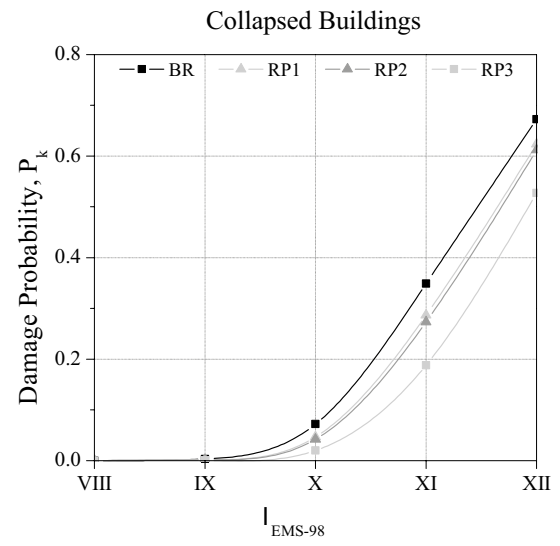

(a)



(b)

Fig. 4. Probability of collapsed (a) and unusable buildings (b) for the different building conditions analysed

Table 5. Estimation of the number of collapsed and unusable buildings, for a total of 192 buildings evaluated

\begin{tabular}{|c|c|c|c|c|c|c|c|c|}
\hline \multirow{2}{*}{$\begin{array}{l}\text { Intensity } \\
I_{\text {EMS-98 }}\end{array}$} & \multicolumn{4}{|c|}{ Collapsed buildings } & \multicolumn{4}{|c|}{ Unusable buildings } \\
\hline & $\mathrm{BR}$ & $\mathrm{RP1}$ & RP2 & RP3 & $\mathrm{BR}$ & RP1 & $\mathrm{RP} 2$ & RP3 \\
\hline VIII & 0 & 0 & 0 & 0 & $9(4.5 \%)$ & $6(3.1 \%)$ & $5(2.8 \%)$ & $3(1.5 \%)$ \\
\hline IX & $1(0.3 \%)$ & 0 & 0 & 0 & $43(22.4 \%)$ & 35 (18.1\%) & 33 (17.1\%) & $22(11.5 \%)$ \\
\hline $\mathrm{X}$ & $14(7.2 \%)$ & $9(4.7 \%)$ & $8(4.2 \%)$ & $4(2.0 \%)$ & $92(47.7 \%)$ & $85(44.1 \%)$ & $83(43.2 \%)$ & $70(36.4 \%)$ \\
\hline $\mathrm{XI}$ & $67(34.9 \%)$ & $55(28.6 \%)$ & $52(27.3 \%)$ & $36(18.8 \%)$ & $91(47.3 \%)$ & $96(49.8 \%)$ & $96(50.2 \%)$ & $100(51.8 \%)$ \\
\hline XII & $129(67.3 \%)$ & $120(62.4 \%)$ & $118(61.2 \%)$ & $101(52.7 \%)$ & $52(27.1 \%)$ & 59 (30.7\%) & 60 (31.5\%) & 72 (37.3\%) \\
\hline
\end{tabular}

considering macroseismic intensities in the range of $I_{\text {EMS-98 }}=$ VIII to $I_{\text {EMS-98 }}=$ XII.

As in the previous case, a proposal of the Servizio Sismico Nazionalle (Bramerini et al. 1995) was used to estimate the casualties (deaths and severely injured) and homeless rates. Regarding the deaths and severely injured rate, it is defined as being $30 \%$ of the inhabitants living in collapsed and unusable buildings. In this case, the survivors assumed to require short-term shelters. Casualties and homeless rates were determined using Eq. (8) and (9), respectively.

$$
\begin{aligned}
& P_{\text {death and severelyinjured }}=0.3 \times P\left(D_{5}\right) \\
& P_{\text {hom eless }}=P\left(D_{3}\right) \times W_{e i, 3}+P\left(D_{4}\right) \times W_{e i, 4}+0.7 \times P\left(D_{5}\right) .
\end{aligned}
$$

Using the same presentation scheme, Figure 5 presents the probability of casualties and homeless

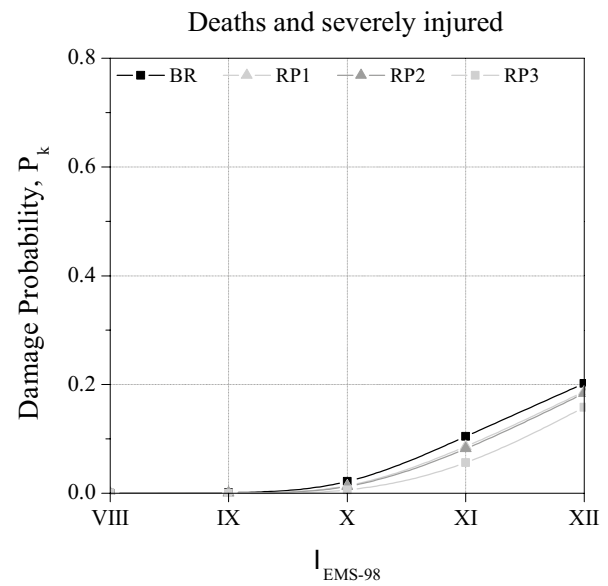

(a)

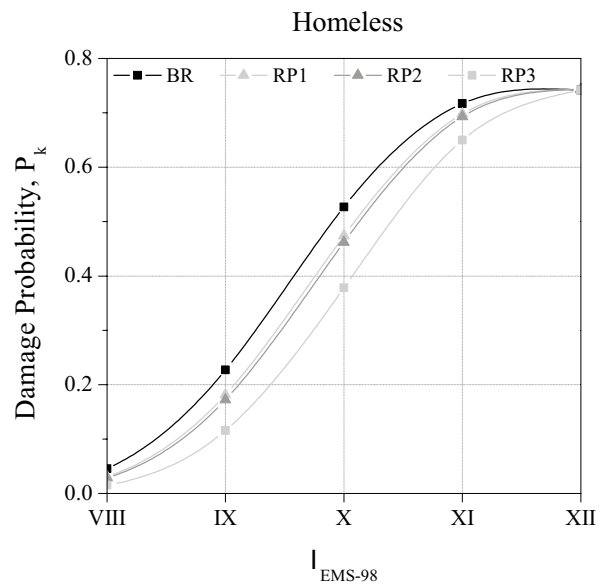

(b)

Fig. 5. Probability of deaths and severely injured (a) and homeless (b) for the evaluated building conditions (BR to RP3) 
Table 6. Estimation of the number of deaths and severely injured, and homeless, for a total number of 1596 inhabitants

\begin{tabular}{|c|c|c|c|c|c|c|c|c|}
\hline \multirow{2}{*}{$\begin{array}{l}\text { Inten- } \\
\text { sity } \\
I_{\text {EMS-98 }}\end{array}$} & \multicolumn{4}{|c|}{ Deaths and severely injured } & \multicolumn{4}{|l|}{ Homeless } \\
\hline & $\mathrm{BR}$ & $\mathrm{RP} 1$ & RP2 & RP3 & $\mathrm{BR}$ & $\mathrm{RP} 1$ & $\mathrm{RP} 2$ & RP3 \\
\hline VIII & 0 & 0 & 0 & 0 & $73(4.5 \%)$ & $49(3.1 \%)$ & $45(2.8 \%)$ & $24(1.5 \%)$ \\
\hline IX & $2(0.1 \%)$ & $1(0.1 \%)$ & $1(0.1 \%)$ & 0 & $363(22.7 \%)$ & $290(18.2 \%)$ & $275(17.2 \%)$ & $185(11.6 \%)$ \\
\hline $\mathrm{X}$ & $34(2.2 \%)$ & $22(1.4 \%)$ & $20(1.3 \%)$ & $9(0.6 \%)$ & $841(52.7 \%)$ & $756(47.4 \%)$ & $737(46.2 \%)$ & $603(37.8 \%)$ \\
\hline $\mathrm{XI}$ & $167(10.5 \%)$ & $137(8.6 \%)$ & $131(8.2 \%)$ & $90(5.6 \%)$ & $1144(71.7 \%)$ & $1114(69.8 \%)$ & $1106(69.3 \%)$ & $1037(65.0 \%)$ \\
\hline XII & $322(20.2 \%)$ & $299(18.7 \%)$ & $293(18.4 \%)$ & $253(15.8 \%)$ & $1184(74.2 \%)$ & $1186(74.3 \%)$ & $1187(74.4 \%)$ & $1184(74.2 \%)$ \\
\hline
\end{tabular}

obtained for each of the building conditions (BR to RP3) for the previous seismic intensity scenarios (from $I_{\text {EMS-98 }}=$ VIII to XII).

In addition, the global frequencies computed from these two probabilistic outputs are given in Table 6, from which it is worth emphasizing the significant decrease of the homeless attained through the application of the retrofitting package solutions. As an example, a decrease of about $15 \%$ was observed in the number of homeless people (from 841 to 603 out of 1596 inhabitants) for an intensity $I_{\text {EMS-98 }}=\mathrm{X}$.

The earthquake that occurred in 2009 in the Italian city of L'Aquila caused about 300 deaths and rendered 40,000 homeless. This example should provide to other countries an important lesson about strategies that disbelieve the community engagement in post-disaster decision-making (Liel et al. 2013). Therefore, it is suggested that both communities and governments should put more emphasis on planning for post-disaster, valuing the community engagement and decision-making, especially planning for emergency response.

\subsection{Economic loss}

In this section, the behavioral influence of the retrofitting packages is analyzed, not only over the estimation of the seismic vulnerability index associated to each, but also how these actions contribute to mitigate the earthquake risk in general. As addressed by Benedetti and Petrini (1984), the mean damage grade, discussed in Section 3.2, can be interpreted either economically or by means of an economic damage index representing the ratio between repair and replacement costs (i.e. building value). The correlation between damage grades and these repair and replacement costs was proposed by Dolce et al. (2006) by processing and analysing postearthquake damage data collected after the Umbria-Marche (1997) and Pollino (1998) earthquakes (Dolce et al. 2006), using the GNDT-SSN procedure (GNDT 1994). From that extensive amount of data, these authors obtained statistical values based on the estimated cost of typical replacement actions applied to more than 50,000 buildings.

Thus, and according to Vicente (2008), the repair cost probabilities for a certain seismic event characterized by an intensity $I, P[R \mid I]$, can be obtained from the product of the conditional probability of the repair cost for each damage level, $P\left[R \mid D_{\mathrm{k}}\right]$, with the conditional probability of the damage condition for each level of building vulnerability and seismic intensity, $\mathrm{P}\left[D_{\mathrm{k}} \mid I_{v}, I\right]$, given by Eq. (10):

$$
P[R \mid I]=\sum_{D_{k}=1 I_{v}=0}^{5} \sum_{I^{\prime}}^{100} P\left[R \mid D_{k}\right] \times P\left[D_{k} \mid I_{v}, I\right] .
$$

To estimate the replacement costs associated with the different building conditions, an average cost value of $700 € / \mathrm{m}^{2}$ was considered for the building stock within the historical centre of the city of Horta, value that was in line with the one estimated by Dolce et al. (2006) from the reconstruction process undertaken in the aftermath of the Irpinia earthquake. Moreover, to account for built and cultural heritage issues, whereas the implementation of traditional building techniques and materials can be slightly more expensive than current solutions, this average cost value per unit area was considered $1000 € / \mathrm{m}^{2}$ for the BR building condition. It is worth noting that this value was already suggested in the past by Vicente et al. (2011) for the old city centre of Coimbra, Portugal.

Based on these probabilistic values it is then possible to estimate the global replacement costs for the entire study area (192 buildings) and to obtain the economic balance computed for each one of the three retrofitting packages, in relation do the BR buildings condition. This output is presented in Figure 6 for macroseismic intensities ranging between $I_{\text {EMS-98 }}=\mathrm{V}$ and XII and shown Table 7 shows in the form of global savings associated to such economic balance. Moreover, the mean periods of inactivity referred by Nunes (2008) for the Archipelago of Azores (i.e. the mean amount of 


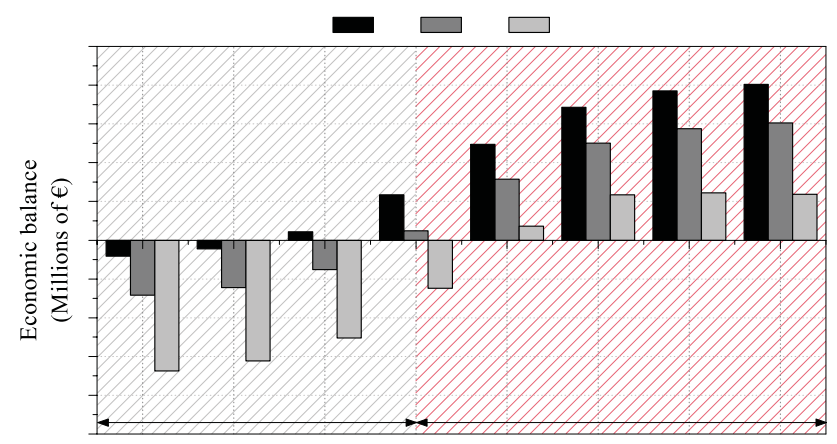

Fig. 6. Economic balance for the three retrofitting packages considered, in relation to the BR building condition

time elapsed between two earthquakes of intensities $\mathrm{V}<I_{\mathrm{EMS}-98}<\mathrm{VIII}$ and $I_{\mathrm{EMS}-98} \geq \mathrm{VIII}$ ), are also presented in Figure 6 so that the economic viability of the retrofitting packages analysed in this work can be easily analysed.

From the analysis of Figure 6, it is easy to conclude that the three retrofitting packages proved to be cost effective for macroseismic intensities equal or higher than $I_{\text {EMS-98 }}=$ IX. Notwithstanding this fact, for intensities of $I_{\text {EMS-98 }}=$ VII and VII respectively, which are already within the mean period of inactivity of 12 years, global savings of about 1.08 and 5.85 million euros (M€) can be obtained with the application of RP1 to the 192 buildings of the old building stock of Horta (see Table 7).

As would be expected, the global savings obtained from the application of the herein analysed retrofitting packages are more expressive for the higher macroseismic intensities, as the reduction on the relative level of damage suffered by the buildings is more important for these intensities, and from a strictly economic point of view $\mathrm{RP} 1$ proved to be the most cost effective retrofitting package with global saving of around 20 million euros. However, it is important to note that these outputs must be seen and analysed along with the already discussed damage scenarios and loss estimation results, since although for some intensities retrofitting packages RP2 and RP3 could lead to lower economic savings but to a significant decrease in terms of human losses. As an example, considering the retrofitting package RP2, which has an estimated cost of $100 € / \mathrm{m}^{2}$, i.e. about $14 \%$ of the mean replacement cost, reductions of about $0.9 \%, 6.5 \%, 3.0 \%$ and $4.5 \%$ were obtained respectively in the ratios of deaths and severely injured, homeless, collapsed and unusable buildings, for a macroseismic intensity of $I_{\text {EMS-98 }}=\mathrm{X}$. Repeating this exercise for the most expensive and complete retrofitting package, RP3, its costs represent about $33 \%$ of the mean replacement cost, but its implementation leads to a reduction of $51.7 \%$ over the mean vulnerability index value, which, in terms of loss estimation for a macroseismic intensity of $I_{\text {EMS-98 }}=\mathrm{X}$, represents a decrease of $1.6 \%, 14.9 \%, 5.0 \%$ and $11.5 \%$ in terms of the respective ratios of deaths and severely injured, homeless and collapsed and unusable buildings.

\section{CONCLUSIONS}

The broad conclusions and recommendations from the exposed work converge towards the enhancement in terms of public awareness and perception, education, training and research concerning the seismic risk mitigation. Ideally, the strategy to mitigate seismic risk should address land use zoning (reducing exposure), planning and of adequate strengthening campaigns and the implementation of seismic building codes suitable both for new and existing structures (reducing the seismic vulnerability of the built environment). Moreover, with an appropriate and assertive policies, financial and institutional supports at both national and local levels it is possible to carry this strategy into a workable action plan.

As expected, in terms of damage and loss estimation, the results achieved for the case study of Horta's historical centre were found, not as impressive as in other potential case studies (e.g. historical centre of Faro city), due to the large influence of the vulnerability index over the loss estimation formulations and to the low range of the obtained vulnerability index values of the evaluated building stock, estimated through the application of the seismic vulnerability index methodology. Despite the simplifications inherent to the methodology itself, these results were well adjusted to the slight damage levels observed in the city of Horta, in the aftermath of the 1998 Azores earthquake.

Table 7. Global savings obtained for each retrofitting package $\mathrm{RP}_{\mathrm{i}}$ (in millions of $€$ )

\begin{tabular}{|c|c|c|c|c|c|c|c|c|}
\hline \multirow{2}{*}{$\begin{array}{l}\text { Retrofitting } \\
\text { package }\end{array}$} & \multicolumn{8}{|c|}{ Macroseismic intensity, $I_{\text {EMS-98 }}$} \\
\hline & $\mathrm{V}$ & VI & VII & VIII & IX & $\mathrm{X}$ & $\mathrm{XI}$ & XII \\
\hline RP1 & - & - & $1.08 \mathrm{M€}$ & $5.85 \mathrm{M} €$ & $12.24 \mathrm{M} €$ & $17.15 \mathrm{M} €$ & $19.23 \mathrm{M} €$ & $20.10 \mathrm{M} €$ \\
\hline RP2 & - & - & - & $1.20 \mathrm{M} €$ & $7.89 \mathrm{M} €$ & $12.53 \mathrm{M} €$ & $14.39 \mathrm{M€}$ & 15.13 M€ \\
\hline RP3 & - & - & - & - & $1.80 \mathrm{M} €$ & $5.86 \mathrm{M} €$ & $6.12 \mathrm{M} €$ & $5.91 \mathrm{M} €$ \\
\hline
\end{tabular}


With respect to the considered retrofitting solutions, their implementation led in general, to a reasonable improvement of the building stock global seismic behaviour, namely in terms of the vulnerability index values, reflecting with great accuracy its known influence over the shear strength capacity, ductility and on the improvement of the so-called box-behaviour. However, from loss estimation results, the enhancement observed by implementing these retrofitting packages could have been more expressive if the building stock seismic vulnerability was higher, therefore implicating higher vulnerability index values.

From the loss estimation results related to collapsed and unusable building rates obtained to the maximum observed macroseismic intensities in Faial of $I_{\mathrm{EMS}-98}=\mathrm{IX}$ and $\mathrm{X}$, it is relevant to point out, on the one hand, an extremely low rate of collapsed buildings, and on the other hand, the significant rate of unusable buildings expected in the event of an earthquake within this range of intensities. With respect to human loss estimation, several factors have contributed to the low numbers attained when compared to the total number of inhabitants estimated for the case study area, among them the pronounced seasonality, low population density and again the low range of vulnerability index values obtained to this particular building stock. Nonetheless, the number of homeless population has resulted quite expressive, naturally following to some extent the trend observed of the rate of unusable buildings. Finally regarding economic losses, it is worth highlighting here that the three analysed retrofitting packages proved to be cost-effective for the highest macroseismic intensities, i.e., from $I_{E M S-98}=$ IX to XII, presenting maximum global savings of about 20.10 million euros. Moreover, for moderate to high macroseismic intensities $\left(I_{E M S-98}=\mathrm{VII}\right.$ and VIII), very interesting savings of about 5.85 and 1.20 million euros were obtained with the application of the retrofitting packages $\mathrm{RP} 1$ and $\mathrm{RP} 2$, respectively.

\section{REFERENCES}

Arshad, S.; Athar, S. 2013. Rural housing reconstruction program post-2005 earthquake - learning from the Pakistan experience. A Manual for Post-Disaster Housing Program Managers. 116.

Astroza, M.; Ruiz, S.; Astroza, R. 2012. Damage assessment and seismic intensity analysis of the 2010 $\left(\mathrm{M}_{\mathrm{w}}\right.$ 8.8) Maule earthquake, Earthquake Spectra 28: S145-S164. http://dx.doi.org/10.1193/1.4000027

Benedetti, D.; Petrini, V. 1984. Sulla vulnerabilita sismica di edifici in muratura: un metodo di valutazione. A method for evaluating the seismic vulnerabili- ty of masonry buildings, L'industria delle Costruzioni (149): 66-74.

Bernardini, A.; Giovinazzi, S.; Lagomarsino, S.; Parodi, S. 2007. Vulnerabilità e previsione di danno a scala territoriale secondo una metodologia macrosismica coerente con la scala EMS-98, in Proceedings of the $12^{\text {th }}$ conference of Italian National Association of Earthquake Engineering - ANIDIS, 10-14 June 2007, Pisa, Italia.

Borg, R. P.; Indirli, M.; Romagnoli, F.; Rochas, C.; Kuzñecova, T. 2014. The ANDROID case study; Venice and its territory: vulnerability and resilience in multi-hazard scenarios, Procedia Economics and Finance 18: 825-836. http://dx.doi.org/10.1016/S2212-5671(14)01008-9

Bothara, J.; Brzev, S. 2011. A TUTORIAL: improving the seismic performance of stone masonry buildings. $1^{\text {st }}$ ed. EERI, Oakland, California, USA.

Bramerini, F.; Di Pasquale, G.; Orisini, A.; Pugliese, A.; Romeo, R.; Sabetta, F. 1995. Rischio sismico del territorio Italiano: proposta per una metodologia e risultati preliminary, Technical report SSN/RT/95/01, Rome, Italy.

Calvi, G. M.; Pinho, R.; Magenes, G.; Bommer, J.; Restrepo-Velez, L. F.; Crowley, H. 2006. Development of seismic vulnerability assessment methodologies over the past 30 years, ISET Journal of Earthquake Technology 43: 75-104.

Cansado, E.; Oliveira, C. S.; Fragoso, M.; Miranda, V. 1998. Regras gerais de reabilitação e reconstrução de edifícios correntes afectados pela crise sísmica do Faial, Pico e São Jorge, iniciada pelo sismo de 9 de Julho de 1998.

Coaffee, J. 2008. Risk, resilience, and environmentally sustainable cities, Energy Policy 36(12): 4633-4638. http://dx.doi.org/10.1016/j.enpol.2008.09.048

Costa, A. 2002. Determination of mechanical properties of traditional masonry walls in dwellings of Faial Island, Azores, Earthquake Engineering \& Structural Dynamics 31(7): 1361-1382.

Costa, A. 2006. Strengthening and repairing earthquake damaged structures, in Oliveira, C.; Roca, A.; Goula, X. (Eds.). Assessing and Managing Earthquake Risk, Chapter 19, Springer Netherlands, 403-426.

Costa, A.; Oliveira, C. S.; Neves, F. 2008. Reinforcing techniques more commonly used in Faial reconstruction. Sismo 1998 - Açores. Uma década depois. $1^{\text {st }}$ ed., 531-555.

Costa, A. A.; Arêde, A.; Costa, A.; Guedes, J.; Silva, B. 2012. Experimental testing, numerical modelling and seismic strengthening of traditional stone masonry: comprehensive study of a real Azorian pier, Bulletin of Earthquake Engineering 10(1): 135-159.

Cunha, S. 2013. Retrofitting techniques of masonry buildings. MSc Thesis. Department of Civil Engineering. University of Aveiro, Portugal.

D'Ayala, D.; Speranza, E. 2002. An integrated procedure for the assessment of seismic vulnerability of historic buildings, in Proceedings of the $12^{\text {th }}$ European Conference on Earthquake Engineering, 2-6 September 2002, London, UK. London: Elsevier Science Ltd. Paper Reference 561.

DM. 2008. Decreto Ministeriale DM 14/01/2008. Norme tecniche per le costruzioni, 428.

Dolce, M.; Kappos, A.; Masi, A.; Penelis, G.; Vona, M. 2006. Vulnerability assessment and earthquake damage scenarios of the building stock of Potenza 
(Southern Italy) using Italian and Greek methodologies, Engineering Structures 28(3): 357-371. http:// dx.doi.org/10.1016/j.engstruct.2005.08.009

Ferreira, T. M.; Vicente, R.; Mendes da Silva, J. A. R.; Varum, H.; Costa, A. 2013. Seismic vulnerability assessment of historical urban centres: case study of the old city centre in Seixal, Portugal, Bulletin of Earthquake Engineering 11(5): 1753-1773.

GNDT. 1994. Scheda di esposizione e vulnerabilità e di rilevamento danni di primo livello e secondo livello (muratura e cemento armato). Grupo Nazionale per la Difesa dai Terrmoti - Servizio Sismico Nazionale, Rome, Italy.

Goula, X.; Roca, A.; Oliveira, C. S. (Eds.). 2006. Assessing and managing earthquake risk. Geo-scientific and engineering knowledge for earthquake risk mitigation: developments, tools, techniques. Springer Netherlands.

Grünthal, G. (Ed.). 1998. European Macroseismic Scale 1998 (EMS-98). European Seismological Commission, Subcommission on Engineering Seismology, Working Group Macroseismic Scales, Luxembourg.

Indirli, M. 2009. Organization of a Geographic Information System (GIS) database on natural hazards and structural vulnerability for the historical centre of San Giuliano di Puglia (Italy) and the City of Valparaiso (Chile), International Journal of Architectural Heritage 3(4): 276-315. http://dx.doi. org/10.1080/15583050902803780

Indirli, M.; Kouris, L. A. S.; Formisano, A.; Borg, R. P.; Mazzolani, F. M. 2013. Seismic damage assessment of unreinforced masonry structures after the Abruzzo 2009 earthquake: the case study of the historical centres of L'Aquila and Castelvecchio Subequo, International Journal of Architectural Heritage 7(5): 536-578. http://dx.doi.org/10.1080/15583058.2011.654050

Indirli, M.; Knezic, S.; Borg, R.; Kaluarachchi, Y.; Ranguelov, B.; Romagnoli, F.; Rochas, C. 2014. The ANDROID case study; Venice and its territory: a general overview, Procedia Economics and Finance 18: 837-848. http://dx.doi.org/10.1016/S22125671(14)01009-0

Kaluarachchi. Y.; Indirli, M.; Ranguelov, B.; Romagnoli, F. 2014. The ANDROID case study; Venice and its territory: existing mitigation options and challenges for the future, Procedia Economics and $\mathrm{Fi}$ nance 18: 815-824. http://dx.doi.org/10.1016/S22125671(14)01007-7

Knezic, S.; Scudeller, M.; Indirli, M.; Romagnoli, F.; Kuzñecova, T.; Perdikou, S. 2014. The ANDROID case study; Venice and its territory: identification of hazards and impact of multi-hazard scenarios, Procedia Economics and Finance 18: 465-472. http:// dx.doi.org/10.1016/S2212-5671(14)00964-2

Liel, A. B.; Corotis, R. B.; Camata, G.; Sutton, J.; Holtzman, R.; Spacone, E. 2013. Perceptions of decisionmaking roles and priorities that affect rebuilding after disaster: the example of L'Aquila, Italy, Earthquake Spectra 29(3): 843-868. http://dx.doi. org/10.1193/1.4000158

Maio, R.; Ferreira, T. M.; Vicente, R.; Estêvão, J. 2015. Seismic vulnerability assessment of historical centres: case study of the old city centre of Faro, Portugal, Journal of Risk Research http://dx.doi.org/10.10 80/13669877.2014.988285
Mazzolani, F. M.; Indirli, M.; Faggiano, B.; Formisano, A.; De Gregorio, D.; Zuccaro, G. 2009. Catastrophic effects of a Vesuvian eruption on the built environment, in Proceedings of the $2^{\text {nd }}$ international workshop on Performance, Protection \& Strengthening of Structures under Extreme Loading PROTECT 2009, 19-21 August 2009, Hayama, Japan.

MEDEA. 2013. Manuale di Esercitazioni sul Danno ed Agibilità per edifici ordinari [User's handbook to check damage and safety/usability for ordinary buildings]. Civil Defense, Italy.

Mitchelson, M. 2011. Haiti and Christchurch earthquakes viewed through a resilience lens - a comparative case study. MSc thesis. Auckland University of Technology, Australia.

Neves, F.; Costa, A.; Vicente, R.; Oliveria, C. S.; Varum, H. 2012a. Seismic vulnerability assessment and characterisation of the buildings on Faial Island, Azores, Bulletin of Earthquake Engineering 10(1): 27-44.

Neves, N.; Arêde, A.; Costa, A. 2012b. Seismic analysis of a building block, Bulletin of Earthquake Engineering 10(1): 235-267.

Nunes, J. 2008. General description of the Azores region seismicity, in Oliveira, C.; Costa, A.; Nunes, J. C. (Eds.). Sismo 1998 -Açores. Uma década depois. $1^{\text {st }}$ Editio. Horta, Faial Island, Azores, Portugal, 59-72.

Oliveira, C. S.; Lucas, A.; Guedes, J. H. C. 1990. 10 Anos após o Sismo dos Açores de 1 de Janeiro de 1980. Monografia, Volume I e II. Secretaria Regional da Habitação e Obras Públicas, Delegação da Ilha Terceira, Açores, Laboratório Nacional de Engenharia Civil, Angra do Heroísmo, Açores, Portugal.

Pagnini, L. C.; Vicente, R.; Lagomarsino, S.; Varum, H. 2011. A mechanical model for the seismic vulnerability assessment of old masonry buildings, Earthquakes and Structures 2(1): 25-42. http://dx.doi. org/10.12989/eas.2011.2.1.025

Ranghieri, F.; Ishiwatari, M. 2014. Learning from Megadisasters: lessons from the Great East Japan Earthquake. International Bank for Reconstruction and Development/The World Bank, Washington DC. http://dx.doi.org/10.1596/978-1-4648-0153-2

Santos, C.; Ferreira, T. M.; Vicente, R.; Mendes da Silva, J. A. R. 2013. Building typologies identification to support risk mitigation at the urban scale - case study of the old city centre of Seixal, Portugal, Journal of Cultural Heritage 14(6): 449-463. http://dx.doi. org/10.1016/j.culher.2012.11.001

Vicente, R. 2008. Estratégias e metodologias para intervenções de reabilitação urbana: avaliação da vulnerabilidade e do risco sísmico do edificado da Baixa de Coimbra. Universidade de Aveiro, Aveiro, Portugal.

Vicente, R.; Parodi, S.; Lagomarsino, S.; Varum, H.; Mendes da Silva, J. A. R. 2011. Seismic vulnerability and risk assessment: case study of the historic city centre of Coimbra, Portugal, Bulletin of Earthquake Engineering 9(4): 1067-1096. http://dx.doi. org/10.1007/s10518-010-9233-3

Zonno, G.; Oliveira, C. S.; Ferreira, M. A.; Musacchio, G.; Meroni, F.; Mota-de-Sá, F.; Neves, F. 2010. Assessing seismic damage through stochastic simulation of ground shaking: the case of the 1998 Faial Earthquake (Azores Islands), Surveys in Geophysics 31(3): 361-381. http://dx.doi.org/10.1007/s10712-009-9091-1 